\title{
Research on the Teaching Skill Training under the Environment of Information Technology
}

\author{
An Wang ${ }^{1, a}$, Rongfei Chu ${ }^{2, b}$ \\ ${ }^{1}$ Education School, Jiangxi Science \& Technology Normal University, Nanchang, China \\ 2 Jiangxi Science \& Technology Normal University, Nanchang, China \\ awanganwangmenghua@163.com; bcrf8899@163.com
}

Keywords: network; teaching skill; microteaching

\begin{abstract}
Microteaching is an effective method of training teaching skills of normal university students. How to use microteaching to train teaching skill under the environment of information technology to improve the training quality is the urgent research subject at present. The paper analyzes the features of classroom teaching under the environment of information technology, and puts forwards the teaching skill training system and training mode. The mode can provide teaching demonstration and excellent lesson for normal university students, offer comprehensive and timely feedback for trainees without the limitation of time and space, and give full play to the advantage of autonomous learning and mutual evaluation. At the same time, the mode is also convenient for teachers to guide the most students timely and improves the training effect.
\end{abstract}

\section{Introduction}

The teaching skill is the necessary occupation skill to be a teacher and is an important factor of teachers' professional development. Training the teaching skill of normal university students by using microteaching method is the basic quality to realize the professional training. The development of educational technology increase new vigor to the microteaching. Using the information technology to record the simulation teaching practice process not only gives full play to the main role of students, but also makes the teachers give timely guidance and evaluation. At present, the microteaching under the information technology environment has become an important method of training teaching skills of normal students and in-service teachers.

\section{The characteristics of the classroom teaching under the environment of information technology}

The application of information technology in teaching has led to changes in the sense of teaching and learning. In traditional classroom teaching, students are the recipients of knowledge and in a passive position. However, after the information technology is brought into classroom teaching, especially the development of network technology, the learning can be carried out on the network, not limited by time and space. In the process of learning, when encountering some difficult problems, in addition to turning to teachers for help, students can also turn to other learners on the network.

The application of information technology in teaching can highlight the focus and break through the difficulty better to improve the classroom efficiency. The core of classroom teaching is to break through the difficulty and highlight the key. The information technology can make the abstract problem pictorial, macroscopic things micro, and micro things macroscopic. The key and difficulty should be the first to teach and then be simulated through the multimedia in the premise of understanding. Teaching is abstract, but the simulation is vivid. So students will be impressive and gradually cultivate the ability of analyzing and solving problems.

The application of information technology in classroom teaching makes the role and status of teachers change. In the traditional classroom teaching, the teachers are to impart knowledge and the instructors, but the application of information technology in teaching makes students acquire 
knowledge through a variety of channels and teachers' role change. Teachers can select suitable teaching mode and diversified teaching methods according to teaching contents, teaching objectives, students' cognitive level and other basis, so their role changes continuously in accordance with the need of teaching. In the teaching process, teachers are the guiders, organizers, and participants, in an equal status with the students.

A large number of information resources and resource libraries under the environment of information technology make the meaning of textbook change. The change is not only reflected in the emergence of the non printing materials (such as optic materials, video teaching materials, network courses, etc), the more important is not affected by past restriction any longer. People will use more teaching material library, teaching resource library, teaching or learning package bag, etc, which can not only let student experience the fun of seeking knowledge, but also find their own useful information in the vast amount of information.

The classroom teaching under the environment of information technology highlights the characteristics of mutual communication and cooperation between students, teachers and students, students and social resources. The learning process will more highlight the division of tasks and responsibilities, mutual collaboration and sharing.

\section{The teaching skill training mode based on information technology}

The teaching skill training based on information technology is the training mode giving prominence to students as the main body and the teachers as the leading. The following is the teaching skill training mode.

Learn the theory of teaching skills. According to the needs of teaching, learn the related theory systematically before training, including the organization of classroom teaching, microteaching theory, classification of teaching skills, teaching design, etc. Study the relevant knowledge of teaching skills autonomously to master the role, purpose, type, implementation strategy and evaluation index system of teaching skills, and then complete the training contents of teaching skills under the guidance of teachers to achieve the training aim.

Inspect and learn from each other' s work. Before training, play some video data. It can be positive, such as excellent teachers' model teaching video, or outstanding cases left by the previous normal students, etc; of course, it can also be counter examples, such as the typical problems existing in the previous training, to do a good job of prevention for the upcoming training. During the playback, the teachers should timely evaluate, guide and inspire students to think the training method of every teaching skill, cultivate students' own induction and selection ability of teaching practice and strategy, so as to improve their self-control ability. Students can also make full use of campus network to find the corresponding information in the micro training video case library to learn autonomously.

Teaching design and write lesson plans. According to the aim of the identified teaching skill, select teaching content and teaching objectives to carry out teaching design. Then write microteaching plans and choose teaching media according to the design.

Simulate and exercise. Students simulate in accordance with the training program in turn. The participants are trainees, their classmates, guiding teachers and reviewers. In addition, provide evaluation table of individual skill training on the basis of the training goal to offer the basis of grading to the reviewers.

Record the video from start to finish. In the process of teaching, the teachers in the central control room will record the trial process sequentially and then upload to the campus network, convenient to self-assessment, peer assessment and comments.

Establish microteaching training video case library. After editing, the training videos are stored in microteaching training video case library to query and retrieval. Video case library provides service for students and teachers with the streaming media, and can be downloaded or browsed freely through the campus network in any place connecting the network. Cases in the bases may include selected cases, live video, typical example, etc. each case should be accompanied by the 
introduction of the background, the analysis, interpretation and evaluation of teachers, expert' comments, applicable object, reference materials, etc. establishing digital video case library can effectively support the microteaching skill training.

Feedback and evaluation. Because students' microteaching practice materials are recorded in the hard disk, they can watch their lecture videos instantly after the training. The management personnel can upload the training data with the streaming media format to the teaching practice column of the website. Then students can watch at any time and any place alone or with others, find out deficiencies, and modify teaching plan for the next training.

Teachers' instruction and the communication between teachers and students. Instructors can conveniently check students' teaching practice through the network at any time and place, and then make analysis and evaluation on the effect of practice. It can be not only carried out through the large screen projection in the classroom to all students, but also can organize students to evaluate and exchange in the discussion area.

\section{Summary}

The microteaching training under the environment of information technology is the promotion of traditional microteaching training and has its unique advantages. The teaching skill training mode under the environment of information technology effectively solves the problems in the training, reflects the students' ideas of cognitive construction, provides convenience for teachers to guide the students timely, expands the exchange and cooperation between teachers and students, and improves the effect of teaching skill training and the utilization rate of microteaching lab.

\section{References}

[1] Jianhua Chen. Analysis on the present situation of micro teaching[J]. Journal of Hainan Normal University, 2008.

[2] Ting Chen. The change and development trend of microteaching under the environment of information technology [J]. Audio visual education research, 2007(6): 93-95.

[3] Yimin Han. The function of microteaching in teaching skill training[J]. Journal of Yulin University, 2003.

[4] Qihua Song. The characteristics and strategies of teachers' teaching behavior under the environment of information technology [J]. Audio visual education research, 2006(8): 25-28.

[5] Lewei Li, Yueling Li. The application research of microteaching in teaching skill training[J]. Journal of educational science of Hunan Normal University, 2010.

[6] Siyan Huang. The construction and implementation of digital microteaching system[J]. Journal of Guangdong Education Institute, 2004(5): 123-124.

[7] Jianliang Yang. The design of digital microteaching system based on the network[J]. Chinese education information, 2010(1).

[8] Jianhui Zhou, Fang Ding. The design of microteaching environment based on the network[J]. Modern education technology, 2007,(1).

[9] Huiwen Ye, etc. Research on the construction of microteaching system and its implementation mode[J]. Audio visual education research, 2006, (7): 70-72. 